\title{
Socio-Cultural Climate of Learning and Pupils' Performance in Primary Schools in Cross River State, Nigeria
}

\author{
Bisong, Nonso \\ Faculty of Education, \\ University of Calabar, \\ Nigeria
}

\author{
Oden, Sarah \\ Faculty of Education, \\ University of Calabar, \\ Nigeria
}

\author{
Bassey, Peter \\ Faculty of Education, \\ University of Calabar, \\ Nigeria
}

\begin{abstract}
This study is set to assess the socio-cultural climate of learning and pupils' performance in primary schools in Cross River State Nigeria. Four objectives were formulated to guide this study. A survey was carried out, using 96 randomly selected primary school pupils and 48 teachers from 16 communities in three Local Government Areas in Cross River State Nigeria. Two instruments were employed for data collection, a 14 item interview schedule for pupils eliciting information on social climate and relationship. Eleven of the items were opened, while three were close ended and an 11 item questionnaire for teachers on conditions of facilities and pupils' performance. Data gathered were analyzed using simple percentages and the pupils' responses to the interview questions were collated and reported. Results were presented in line with the objectives of the study. Summary of the results revealed that socio-cultural climate of learning, has tremendous impact on pupils' performance. It was discovered that most pupils tested on literacy and numeracy skills especially, performed below average, Moreover, teachers' responses confirmed that facilities in primary schools are in a very deplorable state, the facilities also show a very poor rating as they indicated. Based on the findings, it was recommended that a conscious effort should be made by managers of education, to create a congenial environment that can enhance effective teaching and learning and facilitate cordial relationship between pupils and with teachers, as well as provide all facilities and infrastructure that can motivate pupils to learn and enhance pupils' optimum performance.
\end{abstract}

\section{Introduction}

The $21^{\text {st }}$ century is characterized by pursuit in excellence and high performance in education. The Nigerian national policy on education and millennium development goals, highlight and prioritize the significance and impact of creating learning environments that will enhance pupils' performance, and lay the foundation for equipping children with functional and saleable skills for sustainable livelihood [1][2][3]. The schools therefore become paramount in this task in ensuring that an appropriate climate, which implores inclusive socio-cultural dimensions, is upheld. This includes school climate and culture, which are two major factors that can enhance or impede pupils' performance in schools [4].

School climate refers to the general ethos or prevalent atmosphere in the school; this is facilitated by the level of interpersonal relationship among pupils, and also with their teachers, evident in a fulfilled sense of belonging and esteem, and pupils' ability to love, work, play and have peace of mind. While school culture, refers to the general beliefs, attitudes and patterns of expected and acceptable behavior that a school upholds, including a conducive physical environment [5][6]. School culture and climate can influence psyche of the pupils and shape their personality and selfconcept which are instrumental ingredients to high performance in school. In Nigeria, and Cross River State in particular, there has been a general concern expressed by the government over the poor performance of pupils in schools. These poor performances have been manifested in the inability of pupils to perform set tasks particularly in numerical and communication skills. Many measures have been adopted by subsequence governments to forestall these. They ranged from extending school hours from $8 \mathrm{am}$ to $5 \mathrm{pm}$ to insisting that extra lessons be given to pupils in school. All these sincere intentions have not improved on the pupils' poor performance; rather it has witnessed a steady decline in performance. This study is couched in Lev Vygotsky's sociocultural theory that stresses the role of social environment and cultural beliefs and attitudes in influencing a child's learning and performance [7]. In recognition of this fact, this study is therefore set to assess the socio-cultural climate of learning has impacted on primary pupils' performance, in Cross River State, Nigeria. 


\section{Objectives}

The following specific objectives have been set to guide the study.

1. To determine the extent to which the physical environment of schools enhances pupils' performance.

2. To establish the nature of relationship between pupils and with their teachers, and the impact it has on their performance.

3. To determine the influence of school culture on primary school pupils' performance.

4. To determine the primary school pupils' performance in literacy, numeracy and life skill acquisition.

\section{Methodology}

A survey of 96 randomly selected primary school pupils and 48 teachers from 16 communities in three local government areas in Cross River State, Nigeria were used. Two instruments were used for data collection, a 14 item interview schedule for pupils eliciting information on social climate and ended questions, while three were open ended. Teachers on the other hand, responded to an 11 item questionnaire on conditions of facilities in the schools and pupils' performance. Data gathered were analyzed using simple percentages and the pupils' responses to the interview questions were collated and reported.

\section{Data presentation and Discussion}

The results of the data analysis are presented in line with the objectives of the study.

Objective I: Extent to which the physical environment of schools enhance pupils' performance.

Table 1. Physical environment of schools and pupils' performance

\begin{tabular}{|l|l|}
\hline Pupils' Responses & $\begin{array}{l}\text { Percentage } \\
\text { Responses }\end{array}$ \\
\hline Do you like your school? & $\mathbf{1 0 0}$ \\
\hline $\begin{array}{l}\text { My School is beautiful with flower } \\
\text { trees. }\end{array}$ & $\mathbf{4 7}$ \\
\hline $\begin{array}{l}\text { We have enough seats in our class } \\
\text { rooms. }\end{array}$ & $\mathbf{3 8}$ \\
\hline Our school has good toilets. & $\mathbf{2 9}$ \\
\hline $\begin{array}{l}\text { There is water flowing in the } \\
\text { school compound. }\end{array}$ & $\mathbf{2 0}$ \\
\hline $\begin{array}{l}\text { Our school has first aid materials } \\
\text { in the box }\end{array}$ & $\mathbf{4 4}$ \\
\hline There is playground in the school & $\mathbf{5 3}$ \\
\hline
\end{tabular}

The Summary of the data above revealed that in the schools sampled, all the children indicated by $100 \%$ that they loved their school, however, it was discovered that they lacked very fundamental and essential facilities that promote a conducive environment for effective teaching and learning. Overall observation of the physical environment of most schools visited, were adjudge to be very unattractive. They had no flower trees, some of the buildings looked rustic with old paints, while some of the physical structures on were moribund. It makes the schools look bare. This is evidenced by the very low percentage in response of pupils who indicated that they lacked good toilets (29\%), drinking water (20\%), enough seats in the classroom $(38 \%)$ and first aid materials $(44 \%)$. Playground, which is very crucial in the overall development of mental and physical health, is indicated by only $53 \%$ of pupils as available in their schools. On siting the playgrounds, it was observed that most of them were not adequate as they were not entirely on flat ground and not grassed. Others were mere spaces existing on the school compound close to the major busy roads.

Table 2. Summary of Teachers' responses on the conditions of facilities in Primary schools in

$$
\text { Cross River State }
$$

\begin{tabular}{|l|l|l|l|l|}
\hline Facility & $\begin{array}{l}\text { Availab } \\
\text { le (\%) }\end{array}$ & $\begin{array}{l}\text { Not } \\
\text { Availab } \\
\text { le (\%) }\end{array}$ & $\begin{array}{l}\text { Adequa } \\
\text { te (\%) }\end{array}$ & $\begin{array}{l}\text { Not } \\
\text { Adequa } \\
\text { te (\%) }\end{array}$ \\
\hline $\begin{array}{l}\text { Drinking } \\
\text { water }\end{array}$ & 8 & 92 & - & - \\
\hline $\begin{array}{l}\text { Toilet for } \\
\text { Boys/Girls }\end{array}$ & 17 & 83 & - & - \\
\hline $\begin{array}{l}\text { School } \\
\text { Library }\end{array}$ & 2 & 58 & 6 & 33 \\
\hline First Aid kit & 33 & 42 & - & 25 \\
\hline $\begin{array}{l}\text { Play } \\
\text { Ground }\end{array}$ & 33 & 17 & - & 50 \\
\hline $\begin{array}{l}\text { Play } \\
\text { equipment }\end{array}$ & 8 & 92 & - & - \\
\hline Laboratory & 6 & 83 & 2 & 8 \\
\hline $\begin{array}{l}\text { Core } \\
\text { Textbooks }\end{array}$ & 23 & - & 10 & 67 \\
\hline
\end{tabular}

Summary of teachers' responses in Table II confirmed that facilities in the primary schools are in a very deplorable state. From the responses, 92\% of teachers indicated that drinking water is not available, while a negligible $8 \%$ say it is available. Considering the importance of water as a life support system, it becomes obvious that its unavailability can destabilize the pupils and disrupt school programs. It was observed that pupils went scouting for drinking water during break period. Their responses in relation to availability of facilities, also show a very poor rating as they indicated that they lacked toilets for boys and girls 
(83\%), school Library (58\%), first aid kit (42\%), play equipment $(92 \%)$, laboratory $(83 \%)$. For playground which $50 \%$ of teachers claimed was inadequate, they were in essence referring to an open field where the children go to play, and most often using dangerous objects such as sharp sticks and stones as a result of lack of play equipment. The physical and mental wellbeing of the pupils are thus not adequately catered for. Similarly, $66 \%$ of teachers responded that core textbooks were inadequate. It follows that if this were so, then pupils' performances which is dependent on such resources is sure to be poor.

To confirm the information provided by the teachers and pupils, the researchers went round to inspect the facilities and found that they were actually in a very deplorable state. Pupils even go into surrounding bushes to defecate as a result of unavailability or dilapidated toilet facilities. This exposes them to the danger of being bitten by reptiles.

Objective II: To establish the nature of relationship between pupils and with their teachers, and the impact it has on their performance.

Table 3. Pupils' responses on relationships with teachers and between pupils

\begin{tabular}{|l|l|}
\hline Pupils' Responses & $\begin{array}{l}\text { Percentage Responses } \\
(\mathbf{\%})\end{array}$ \\
\hline Our teachers treat us well & 84 \\
\hline $\begin{array}{l}\text { Our teachers encourage us } \\
\text { to learn }\end{array}$ & 81 \\
\hline $\begin{array}{l}\text { There is no fighting in our } \\
\text { school }\end{array}$ & 11 \\
\hline
\end{tabular}

Results on the table above shows that $84 \%$ of the pupils stated that their teachers teach them well, and $81 \%$ said that they encouraged them to learn. This revealed a high level of positive relationship between teachers and pupils, while only $11 \%$ indicated that there is no fighting in their school showing a significant negative relationship between pupils. To further probe the nature of existing relationship between teachers and pupils, the researchers through an interview, sought to know three things the pupils would want their teachers to stop doing for them to enjoy their schooling. The most frequently recurring responses were that the teachers should stop flogging them unnecessarily; teachers should love all the pupils equally and stop senior pupils from bullying the junior ones. Others were that teachers should stop using pupils for manual labour, both in the school compound and their personal farms, especially under the hot sun. They also wanted an end to corporal punishment, especially unjust punishment such as kneeling down and carrying of cement blocks. They also would like their teachers to correct them, rather than abuse them verbally. These responses go to confirm that relationship with teachers is not cordial, the pupils dread most of their teachers, and could not imagine relating their problems to them. It also confirmed that the relationship between junior and senior pupils is strained. The pupils strongly appealed that their teachers should intervene as the threat of bullying is a major distraction to schooling. This result revealed that the entire interpersonal relationship between pupils and with their teachers is not healthy and would not enhance the performance of pupils.

Objective III: To determine the influence of school culture on primary school pupils' performance.

To determine the extent to which pupils considered school culture as an important factor in their academic performance, the researchers, in an in depth interview, sought to know what the pupils considered the appropriate inputs that would sustain their interest in school. Pupils' responses yielded information that bordered on provision of toilets, core textbooks, drinking water, and library stocked with books, sufficient seats for pupils as some of them sat on bare, and sometimes unplastered and dusty floor. They also craved for a good and beautiful learning environment, laboratory, provision of electricity, computers, enough classrooms, sporting equipment and school band. Pupils equally wanted their school compound to be fenced for adequate security as in some schools they claimed that hoodlums hang around to rob and chase both pupils and staff. They also wanted their teachers to show them love and correct them when they go wrong rather than beat or flog them. Further probing revealed that an aspect of the school culture was that teachers made pupils to work in both the school farm and their personal farms. They also made pupils to carry babies for the teachers as well as do domestic chores for them. These included going to market to shop for teachers on market days during school hours, picking vegetables and doing laundry for them. While teachers see these practices as normal, and part of the privileges they enjoy teaching in some of these rural schools, the pupils are unhappy because such practices interfere with their lesson periods and study time at school. On the site survey, revealed to the researchers that pupils had no seats, others had seats that were poorly constructed or make shift. Many pupils sat on the bare floor in often uncompleted or dilapidated buildings with leaking roofs and without windows. This entire dehumanizing scene and ways of doing things, which has become a norm, has greatly 
affected the psych of these primary school pupils. It is not then surprising that pupils' performance in school is not impressive.

Objective IV: To determine the primary school pupils' performance in literacy, numeracy and life skill acquisition.

Table 4. Teachers' rating of primary school pupils' performance

\begin{tabular}{|l|l|l|l|l|l|}
\hline & $\begin{array}{l}\text { Very } \\
\text { High }\end{array}$ & High & Average & $\begin{array}{l}\text { Below } \\
\text { Average }\end{array}$ & Poor \\
\hline Literacy & & $8 \%$ & $85 \%$ & $6 \%$ & \\
\hline Numeracy & & $10 \%$ & $79 \%$ & $6 \%$ & $4 \%$ \\
\hline Life Skills & & $17 \%$ & $54 \%$ & $19 \%$ & $10 \%$ \\
\hline
\end{tabular}

The data above shows the teachers' ratings of pupils' performance in the schools visited. It revealed that the average performance of pupils is on the average in Literacy (85\%), Numeracy (79\%) and Life skills (54\%). On a random spot assessment of pupils in schools visited, it was discovered that most pupils tested on literacy and numeracy skills especially, performed below average, contrary to the teachers' ratings. It was noted that they could not solve simple additions and could not read, evidenced from the fact that the questionnaire was read out and filled for them, while they supplied the answers. The poor performance of pupils is attributed to the deplorable learning environment and poor school culture, where most essential school inputs were conspicuously unavailable.

\section{Conclusion}

In view of the findings of this study, it is obvious that for the pupils' performance to be enhanced there must be a conscious effort by managers of the education system to create a congenial environment that can enhance effective teaching and learning. Such an environment should not be oppressive; rather it should facilitate cordial relationships between teachers with pupils, as well as contain basic facilities and infrastructure. Although the state government has embarked on the renovations of some school buildings, and the United Nations Education Fund (UNICEF) has contributed a lot through donations of core text books to some schools and building of some school toilets. Efforts need to be stepped up by the state government to ensure that the school environment be made learner friendly in order to enhance pupils optimum performance.

\section{References}

[1] Federal Republic of Nigeria, (2004). National Policy on Education $4^{\text {th }}$ edition. Lagos: NERDC press

[2] Arief Darmanegar, L. (2006). The influences of sociocultural and educational contexts on approaches to learning.

http://scholarbank.nus.edu.sg/handle/10635/15181. Retrieved on $10^{\text {th }}$ October, 2012.

[3] Woolfolk, A. (2010). Educational Psychology, Global Edition New Jersey: Pearson Education Inc.

[4] Tableman, B., (2004). Best Practice Briefs: School climate and learning, No. 31.

Outreach.msu.edu/bpbriefs/issues/briefs31.pdf. Retrieved on $10^{\text {th }}$. October, 2012.

[5] Oladele, J. O., (2005). Fundamentals of Educational Psychology. Lagos: Johns-Lad Publishers Ltd.

[6] Chauhan, S. S., (1984). Advanced Educational Psychology. New Delhi: Vikas Publishing House.

[7] Scherba de Valenzuela, J., (2002). What is sociocultural theory?

www.unm.edu/devalenz/handouts/sociocult.htm. Retrieved on $10^{\text {th }}$. October, 2012. 